\title{
Gender differences in Obeying Traffic Regulations and the Related Cognitive Factors among Elementary School Students in Khorramabad City: Application of Health Belief Model
}

Maryam Ghavami

MSc. Student in Health Education and Health Promotion, School of Health, Alborz University of Medical Sciences (ABZUMS), Karaj, Iran

Tayebeh Fasihi Harandi

*Assistant Prof., Social Determinants of Health Research Center, Department of Health, ABZUMS, Karaj, Iran. (Corresponding Author)

tfasihih@gmail.com

Kourosh Kabir

Assistant Prof., Dept. of Social Medicine, School of Medicine, ABZUMS, Karaj, Iran

Saeed Saadatmand

Lecturer, Dept. of Psychology, Faculty of Psychology, Payame Noor University (PNU), Tehran Branch, Tehran, Iran

Received: 26 December 2015 Accepted: 7 December 2016

\section{ABSTRACT}

Background and objective: Vehicles are one of the most common causes of accidents among school students. Therefore, this research was conducted to determine the gender differences in obeying traffic regulations and the related cognitive factors among elementary school students in Khorramabad City, Iran. Materials and methods: This was a descriptive and correlational comparative study. 360 elementary school students in Khorramabad City in the year 20142015 were selected through multistage sampling method which answered the demographic questionnaire and questions related to health belief model (HBM) structures and behaviors. The data were analyzed using SPSS20 through Pearson Correlation, Stepwise Regression, Wilk's Lambda and multivariate analysis of variance (MANOVA) tests.

Results: Perceived self-efficacy, perceived barriers and perceived benefits could predict $21.4 \%$ of the changes related to the variable of obeying traffic regulations. Meanwhile, there was a statistically significant difference among female and male students in HBM structures and behavior.

Conclusion: Male students were less informed of HBM structures and behavior compared to female students. Thus, it is necessary to use HBM-based teaching to promote safety culture among students (especially male students).

Paper Type: Research Article.

Keywords: Gender differences, Traffic behaviors, Obeying traffic regulations, Health Belief Model (HBM), Bushehr.

Citation: Ghavami M, Fasihi Harandi T, Kabir K, Saadatmand S. Gender differences in Obeying Traffic Regulations and the Related Cognitive Factors among Elementary School Students in Khorramabad City: Application of Health Belief Model. Iran J Health Educ Health Promot. Autumn 2016;4(3): 217-225. 


\section{تفاوتهاى جنسيتى در رعايت مقررات راهنمايى و رانندكى و عوامل شناختى مرتبط با آن در دانش آموزان مقطع ابتدايى شهر خرمآباد: كاربردى از التَوى اعتقاد بهداشتى}

\begin{abstract}
بك

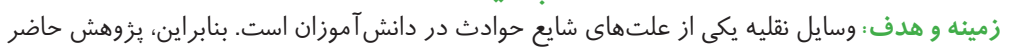

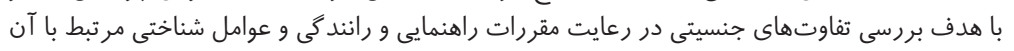

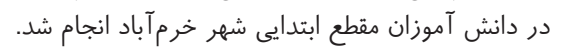

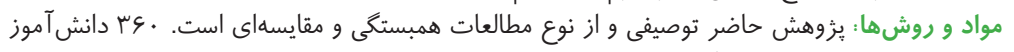

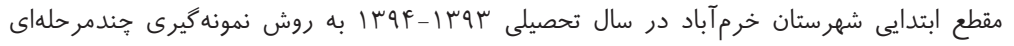

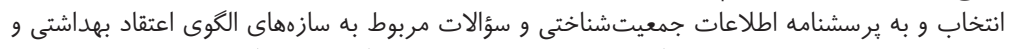

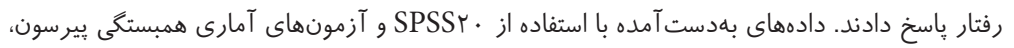

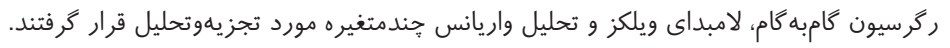

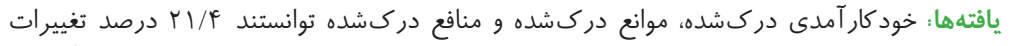

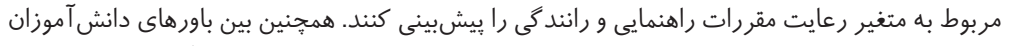

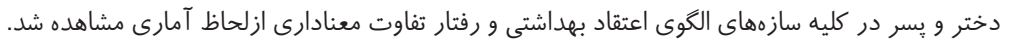

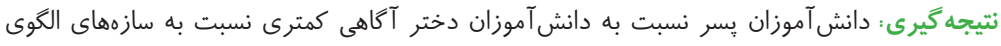

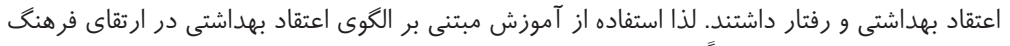

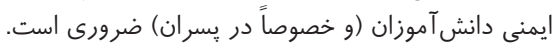

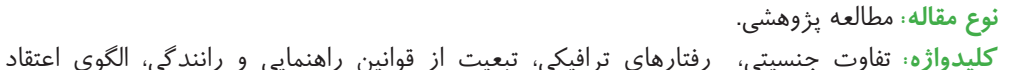
بهداشتى، بوشهر.

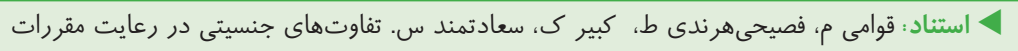

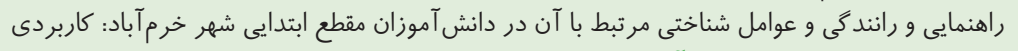

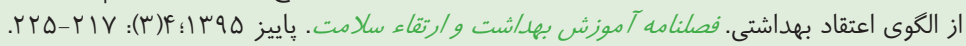

دانشجوى كارشناسى ارشد آموزش بهداشت و ارتقاء

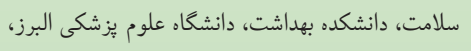

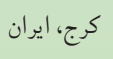
طيبه فصيحى هرندى استى

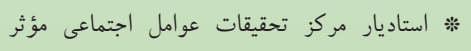

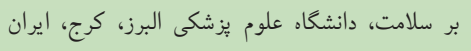

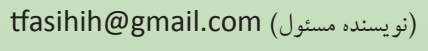

كوروش كبير

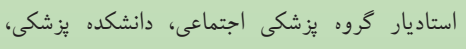
دانشگاه علوم يزشكى البرز، كرج، ايران إنيان سعيد سعادتمند مربى كروه روانشناسى، دانشكده روانشناسى، دانشكاء ييام نور، واحد تهران، تهران، ايران

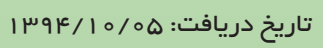

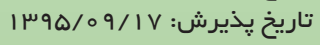




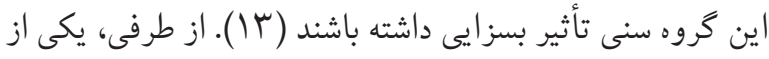

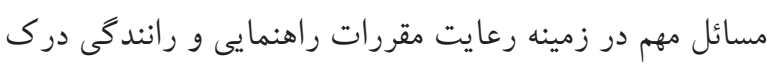
رفتارهاى عابران يياده و ارزيابى صحيح آنها در اين زمينه است.

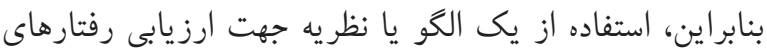

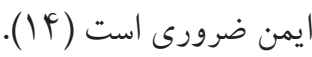

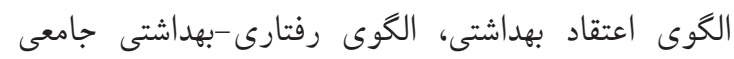

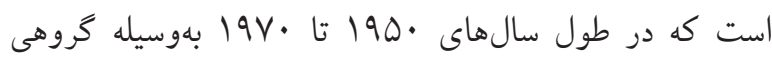
از متخصصين بهداشتى و روانشناسان اجتماعى به دليل قبول نكردن مسائل بهداشتى توسط افراد جامعه و براى رسيدن رون به هدف آموزش بهداشت، يعنى تغيير رفتارهاى بهداشتى،

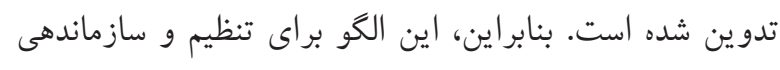
موضوع اين مطالعه انتخابشده است تا راهكارهايى اساسى را باسي براى جستجوى اطلاعات، علاقهند شدن و انخيزش به سمت تصميم گيرى جهت اتخاذ رفتارهاى بيشگيرى كننده از حوادث

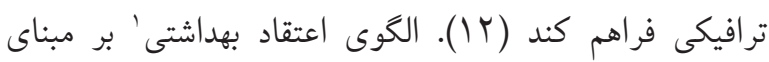
سازهایى خود به بيش بينى رفتار نيز مى يردازد. بنابر اين، مى توان

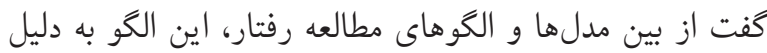

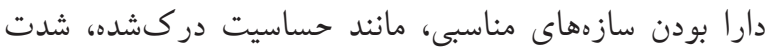
دركشده، منافع دركشده، موانع دركشده، راهنمايى براى عمل مانل و خودكار آمدى كارايى بهترى بهمنظور بيشكويى و تغيير رفتار

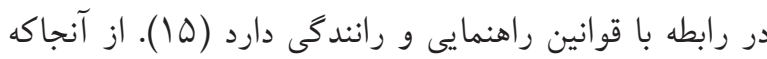
نوجوانان تمايل بيشترى به انجام رفتارهاى برخطرى مانند

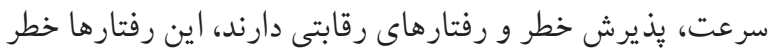

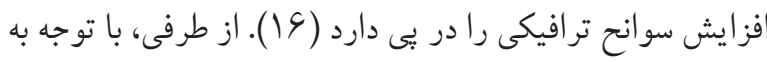
اينكه استان لرستان و مخصوصاً شهر خرم آباد ارتباط دهنده مركز و شمال كشور به جنوب و جنوب غرب است، سالانه ميليونها نفر

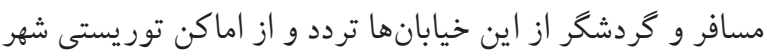

امروزه حوادث جادهاى و خسارات ناشى از آن يكى از جالشهاى عمده جوامع بشرى است. اين حوادث هزينههاى مالى زيادى

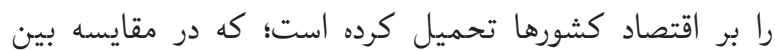
كشورهاى ويشرفته و درحالتوسعه، بيشتر قربانيان اين معضل

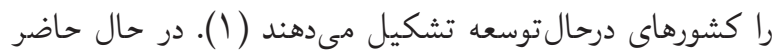
تصادفات جادهاى هشتمين علت DALY (سالهاى ازدسترفته زندگى با ناتوانى يا معلوليت) و يازدهمين علت مرگومير درئ سراسر جهان است و تا سال •Y.Y. به سومين علت مرگومير در جهان تبديل خواهد شد (Y). بيش از •9٪ حوادث ترافيكى

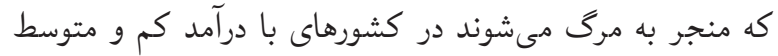

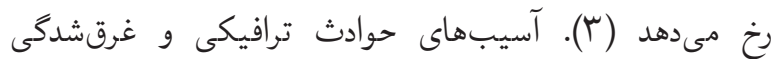
دو علت اصلى مرگومير در كودكان بهخصوص در كشورهاى

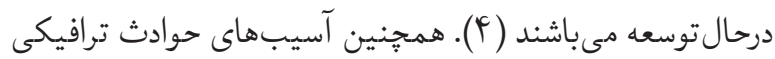
علت اصلى مرگومير در ميان كودكان •|19 19 سال در سراسر

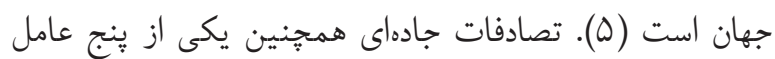
اصلى علتهاى مرگومير در كشورهاى جنوب شرقى آسيا است؛

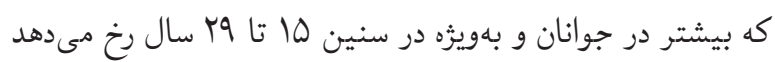

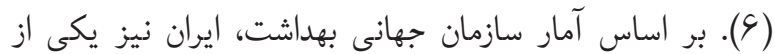

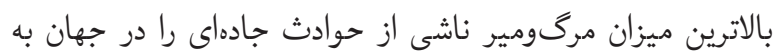
خود اختصاص داده است. به گونهاى كه تصادفات ترافيكى دومين علت مرگومير در اين كشور است (Y). بر اساس نتايج مطالعه

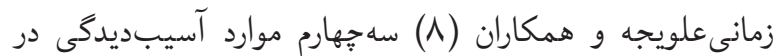

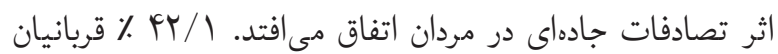

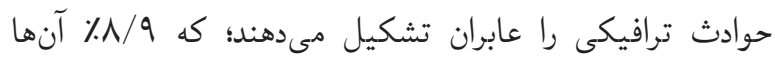
كودكان هستند (9). جهار عامل انسانى، جاده، وسايل نقليه و و محيط مهمترين عوامل در وقوع حوادث ترافيكى هستند ( •().

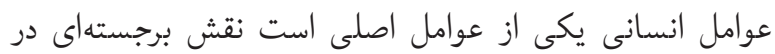

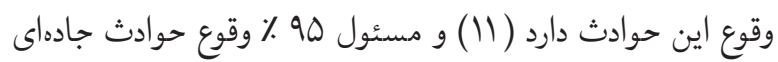

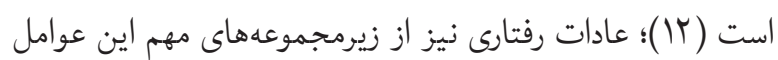
انسانى است (II). 
از צY سؤال تشكيل شده بود: F سؤال حساسيت دركشده، 9 سؤال

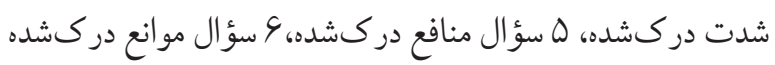

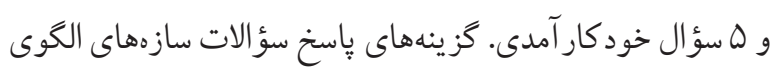
اعتقاد بهداشتى بهصورت طيف ليكرت ه قسمتى (از كاملاً موافقم

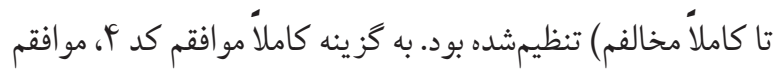
كد ب، نظرى ندارم كد ب، مخالفم كد ا و كاملاً مخالفم كد صفر داده

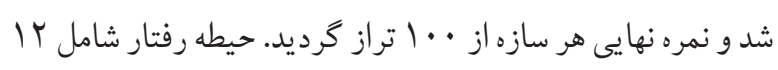

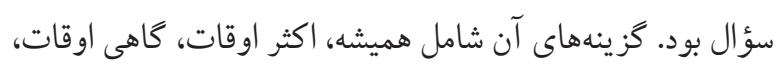

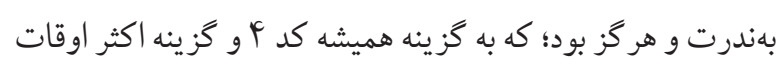

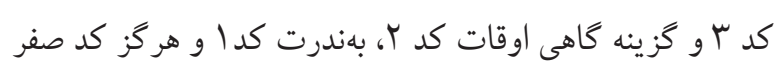

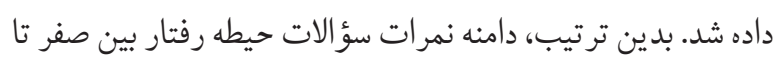

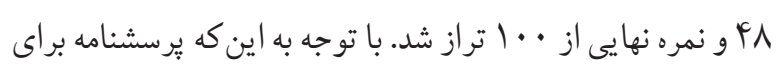

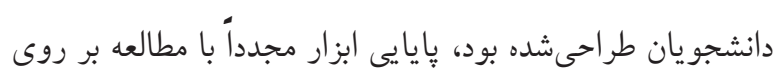

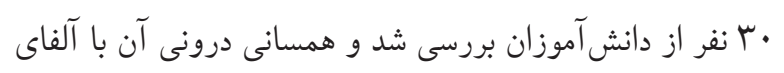

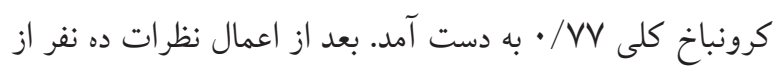

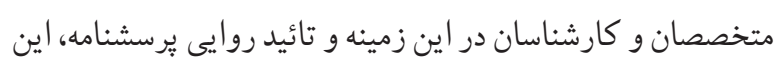
ابزار جهت دانش آموزان مورداستفاده قرار كرفت.

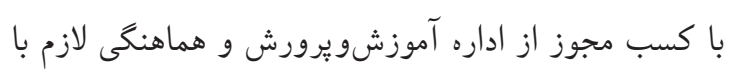

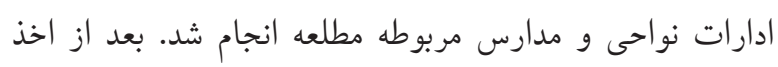

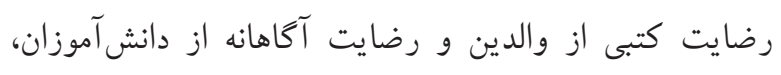

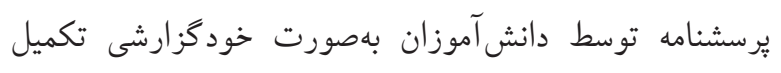

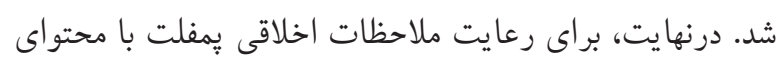

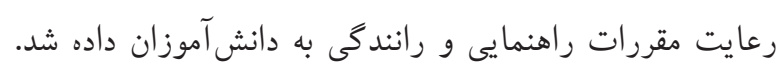

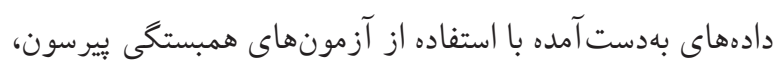

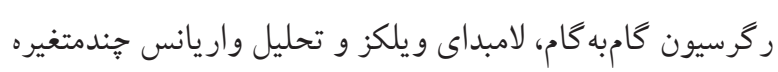
مورد تجزيهو تحليل قرار گرفتند.

يافته ها

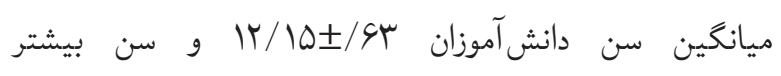

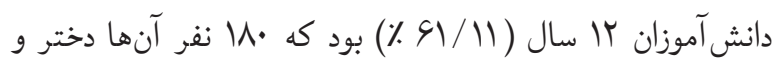

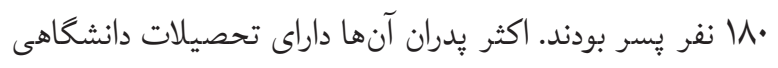

بازديد مى كنند. با توجه به محدود بودن يل هاى هوايى در سطح

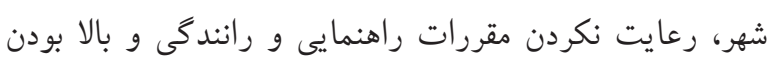

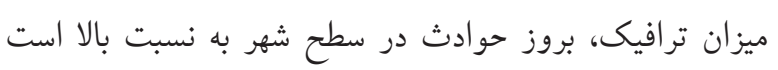
(IV)

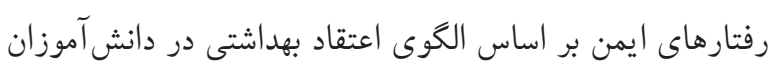

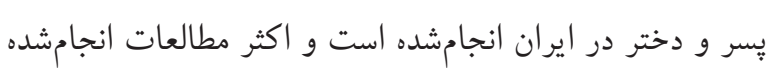

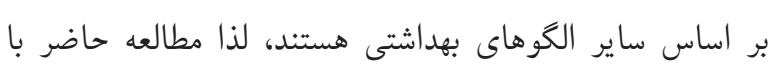

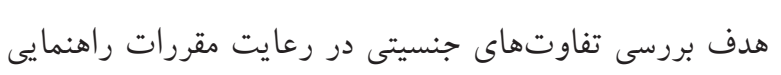

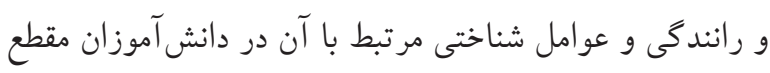

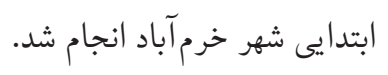
مو اد و روش ها يثوهش حاضر توصيفى و از نوع مطالعات همبستكى و مقايسهاى

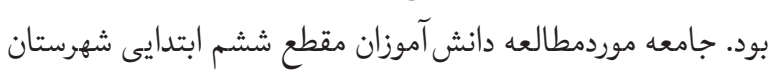

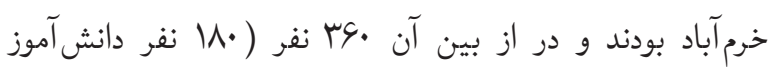

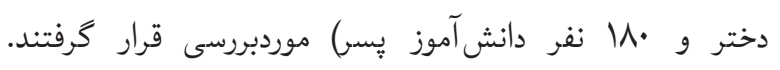
نمونه گيرى بهصورت تصادفى خندمرحلهاى طبقاتى انجام گرفت.

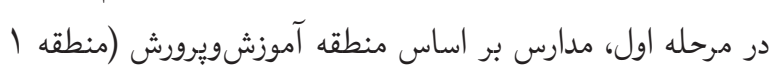

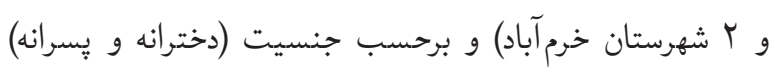

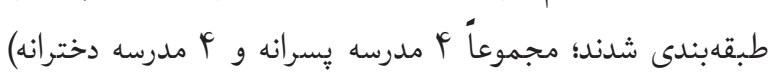
بهصورت تصادفى انتخاب شدند. در مرحله آخر نيز در هر مدرسه يكى از كلاسهاى مقطع ششم بهصورت تصادفى انتخابشده و

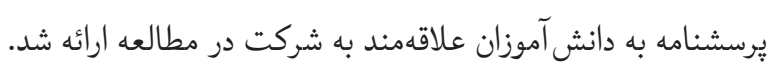

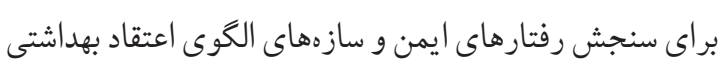

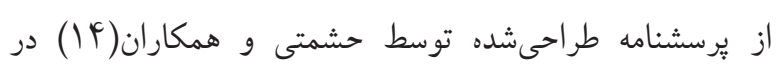

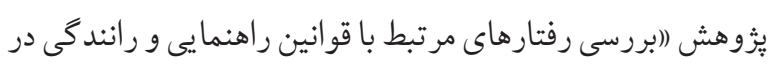

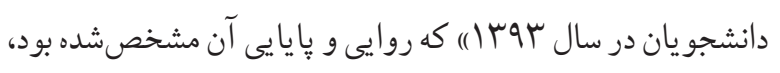

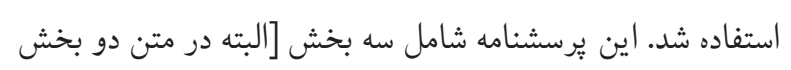

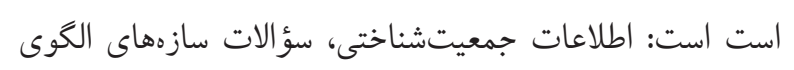

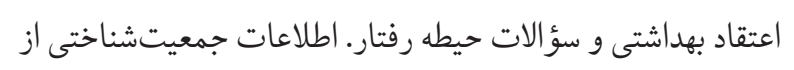

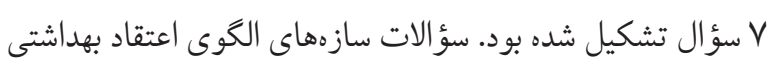


جدول r. . يافته هاى توصيفى متغير هاى مورديثروهش برحسب جنسيت

\begin{tabular}{|c|c|c|c|c|c|c|}
\hline \multicolumn{2}{|c|}{ كل (· •وس نفر) } & \multicolumn{2}{|c|}{ يسر (•1^ نفر) } & \multicolumn{2}{|c|}{ دختر ( •11 نفر) } & آزمودنى \\
\hline SD & M & SD & $\mathbf{M}$ & SD & $\mathbf{M}$ & متغير \\
\hline$\mu / .$. & $\mid r / \wedge \Lambda$ & $r / I V$ & $|r / \Delta|$ & $r / V V$ & $\mid \mu / Y F$ & حساسيت \\
\hline$F / \varepsilon \wedge$ & $10 / 09$ & $F / F G$ & $10 / 11$ & $F / \wedge \Delta$ & $19 / \cdot 1$ & شدت \\
\hline$r / 1$ & $10 / 19$ & $\mu / \Delta$ & $\mid F / F \wedge$ & $r / \cdot r$ & $10 / 9$. & منافع \\
\hline$r / 1$ & $I O / V Y$ & $4 / 19$ & $14 / 94$ & $F / 90$ & $\mid s / 4 \wedge$ & موانع \\
\hline$r / \Delta \varphi$ & $|r / v|$ & r & $\mid$ N & $r / s V$ & $\mid f / \cdot r$ & خود كار آمدى \\
\hline V/AY & $r r / 9 \Lambda$ & $V / 9 r$ & $r \mid / v 1$ & V/Or & $M F / T F$ & رفتار \\
\hline
\end{tabular}

يافتهاى جدول Y نشان مىدهد كه در همهمتغيرهاى مورديزوهش ميانخين نمرات دختران از يسران بيشتر است.

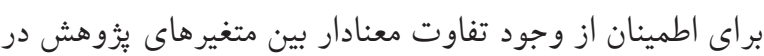

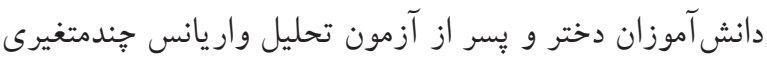

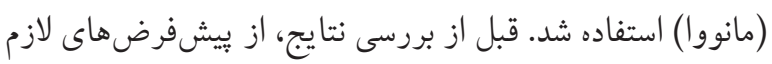
براى استفاده از تحليل واريانس جندمتغيرى (مانووا) اطمينان حاصل شد. تحليل مقدماتى آزمون امباكس نشان داد كه سطح

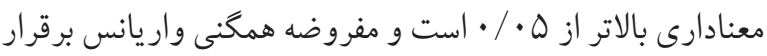

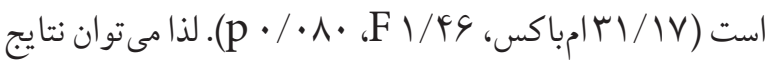

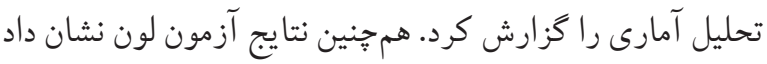
كه يِشفرض همكنى واريانسها در متغيرهاى موردبررسى در

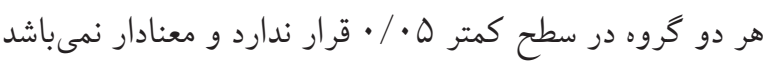

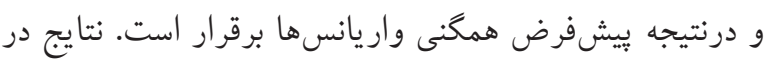

$$
\text { جدولهاى شماره ب و F آمده است. }
$$

جدول س. نتايج آزمون لانداى ويلكز تحليل واريانس جندمتغيره

\begin{tabular}{|c|c|c|c|c|c|c|}
\hline آمارى & p & خطا DF & $\begin{array}{c}\text { DF } \\
\text { مفروض }\end{array}$ & F & آماره & آزمون \\
\hline 1 &.$/ \ldots 1$ & r & 4 & $\Delta / \wedge \Lambda$ & .191 & لانداى \\
\hline
\end{tabular}

نتايج آزمون لانداى ويلكز تحليل واريانس جندمتغيره در جدول ب نشان داد كه بين متغيرهاى مورديزّوهش در دانش آموزان

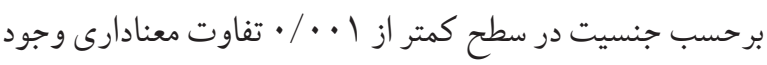
دارد. اين نتايج نشان مىدهد كه در حداقل يكى از متغيرهاى

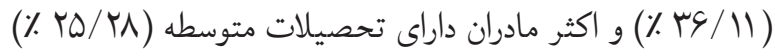
بودند. بيشتر بدران كارمند (

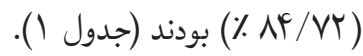

جدول ا. مشخصات جمعيتشناختى دانشآموزان

\begin{tabular}{|c|c|c|c|c|}
\hline معنادارى سطح & درصد & فراوانى & شاخص & متغير \\
\hline 1 & $\begin{array}{l}\Delta . \\
\Delta .\end{array}$ & $\begin{array}{l}11 . \\
11 .\end{array}$ & دخر & جنس \\
\hline.$/ \cdots 1$ & $\begin{array}{l}I Y / T Y \\
S I / 11 \\
r G / G V\end{array}$ & $\begin{array}{l}\text { FF } \\
r Y . \\
q G\end{array}$ & $\begin{array}{l}11 \\
11 \\
11\end{array}$ & سن \\
\hline$\cdot 1 \cdot \cdot 1$ & $\begin{array}{l}1 \cdot 100 \\
r \cdot 100 \\
18 / 11 \\
18 / 90 \\
r s / 11\end{array}$ & $\begin{array}{l}\text { ru } \\
v e \\
\Delta \Lambda \\
g . \\
i r .\end{array}$ & دابتدايى & تحصيلات پدر \\
\hline$\cdot / \cdots 1$ & $\begin{array}{l}11 / 1 \mid \\
r \mu / . q \\
19 / r q \\
r \Delta / r A \\
r F / 19\end{array}$ & $\begin{array}{l}p \cdot \\
\Delta r \\
\Delta q \\
91 \\
\Delta V\end{array}$ & مابت سيكايى & تحصيلات مادر \\
\hline.$/ \cdots 1$ & $\begin{array}{l}F r / A q \\
r V / r T \\
\Delta / r \Lambda \\
1 \cdot / r A \\
1 \% / r r\end{array}$ & $\begin{array}{l}101 \\
91 \\
19 \\
4 V \\
41\end{array}$ & 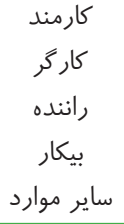 & شغل پِدر \\
\hline.$/ \ldots 1$ & $\begin{array}{l}11 / 11 \\
\Lambda F / V Y \\
r / 1 V\end{array}$ & $\begin{array}{l}r \cdot \\
r \cdot 0 \\
10\end{array}$ & خانهاردار & شغل مادر \\
\hline
\end{tabular}

نتايج مربوط به تفاوت متغيرها برحسب سن دانش آموزان

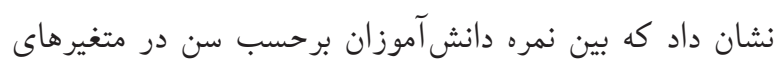
حساسيت دركشده، شدت دركشده، منافع دركشده، موانع

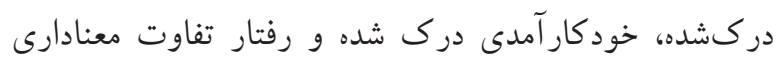
ازلحاظ آمارى وجود ندارد. يافتهاى توصيفى متغيرهاى مورديُّوهش برحسب جنسيت

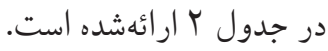


نتايج ارائهده در جدول f ن نشان مىدهد كه بين نمره دانشآموزان دختر و پسر در متغيرهاى حساسيت دركشده،

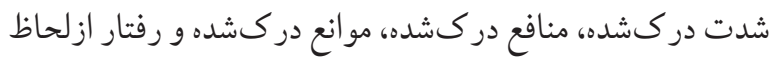
آمارى تفاوت معنادارى وجود دارد و ميانخين نمره دانش آموزان دختر از دانشآموزان بِر در اين متغيرها بيشتر است. اما بين

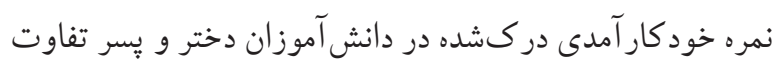

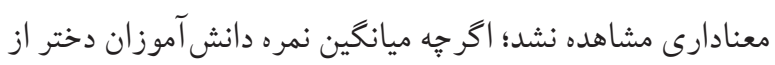
يسر در اين متغير بيشتر بود. در جدول ه ماتريس همبستكى بين سازههاى الكوى اعتقاد

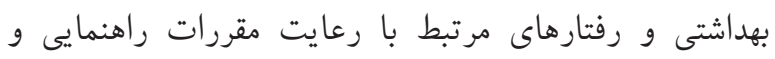
رانند گى ارائهده است.
مورديزوهش برحسب جنسيت در دانش آموزان تفاوت وجود دارد. توان آمارى ا حاكى از كفايت حجم نمونه است. جدول عا. نتايج تحليل واريانس جندمتغيره متغيرهاى مورديثوهش در دانش آموزان برحسب جنسيت

\begin{tabular}{|c|c|c|c|c|c|}
\hline معنادارى سطح & F آماره & مربعات مينكين & آزادى درجه & مربعات مجمع & متغير ها \\
\hline$\cdot / \cdot r_{1}$ & $\Delta /{ }^{\prime} \wedge$ & $F V / S V$ & 1 & $F V / G V$ & حساسيت درك شده \\
\hline$\cdot / \cdot \Delta \cdot$ & r/A & $\Lambda F / 1$. & 1 & $\Lambda F / 1$. & شدت درك شده \\
\hline.$/ \ldots$ & $19 / 9$. & $1 \Lambda \cdot / \& \mu$ & 1 & $1 \Lambda \cdot / \varepsilon \mu$ & منافع درك شده \\
\hline.$/ \ldots$ & $1 r / r q$ & $r \cdot V / \cdot r$ & 1 & $r \cdot V / \cdot r$ & موانع دركشده \\
\hline$\cdot / \cdot 11$ & $r / .4$ & rN/sᄉ & 1 & 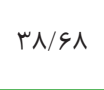 & خود كار آمدى \\
\hline$\cdot / \cdot r$ & $9 / V r$ & $\Delta \Lambda \cdot / / F$ & 1 & $\Delta \Lambda \cdot / l F$ & رفتار \\
\hline
\end{tabular}

جدول ه. ماتريس همبستخى بين سازههاى الكَوى اعتقاد بهداشتى و رفتارهاى مر تبط با رعايت مقررات راهنمايى و رانندگى

\begin{tabular}{|c|c|c|c|c|c|}
\hline منافع دركشده & موانع دركشده & شدت دركشده & حساسيت دركشده & رفتارهاى مرتبط با رعايت مقررات & متغير \\
\hline & & & & - & رفتارهاى مرتبط با رعايت مقر رات \\
\hline & & & - & ./1人米米 & حساسيت دركشده \\
\hline & & - & ./Yৎ米米 &.$/ 1 F *$ & شدت درك شده \\
\hline & - &.$/ 11 * 6$ & ./rr米米 & . / IV米米 & موانع درك شده \\
\hline - & $\cdot / 1$ 人米米 & $\cdot /$ ऍ米米 &.$/ 1 F *$ & . $/$ ऍ米米 & منافع دركشده \\
\hline . / F个粎 & . $/ 19$ 米米 & ./r与米米 &.$/ .9 *$ & . / ץ 粠米 & خود كار آمدى دركشده \\
\hline
\end{tabular}

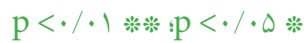

همانطور كه جدول شماره ه نشان مىدهد بين رفتارهاى وجود دارد.

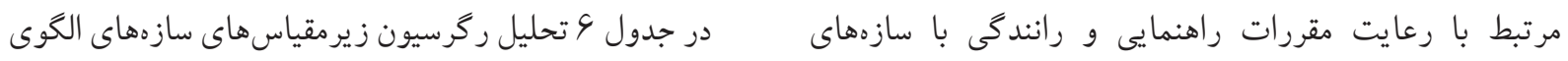

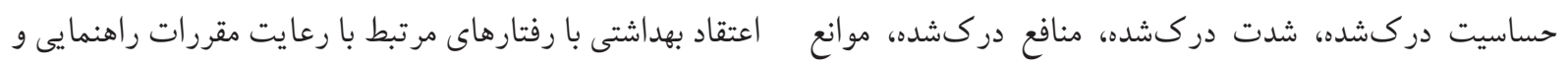

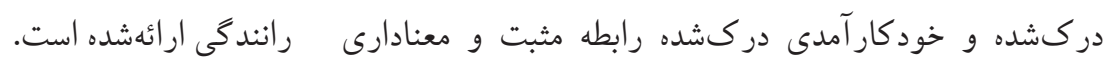

جدول و. تحليل رگَرسيون زيرمقياسهاى سازههاى الگَوى اعتقاد بهداشتى با رفتارهاى مر تبط با رعايت مقررات راهنمايى و رانندگى

\begin{tabular}{|c|c|c|c|c|c|c|c|c|c|c|}
\hline $\mathrm{p}$ & F & Change Rr & Rr & $\mathrm{R}$ & $\mathrm{p}$ & $\mathrm{t}$ & $\beta$ & B & & متغير \\
\hline.$/ .1$ & S9/9T & . $\mid s^{\mu}$ &.$/ 191$ & $\cdot / F \cdot r$ &.$/ . .1$ & N/rs & $\cdot / q \cdot q$ & $\cdot / 19$ & كام اول & \multirow{3}{*}{ رفتار هاى مرتبط } \\
\hline.$/ . .1$ & $r \Delta / \Lambda \Lambda$ & $.1 .+1$ &.$/ \mu_{0}$ & . For &.$/ . .1$ & $r / \mu$. & $\cdot / r \cdot \Delta$ &.$/ \% q$ & كام دوم & \\
\hline.$/ . .1$ & $r \mu / \Delta \Lambda$ & .1 .19 & $\cdot|r| f$ &.$/ q v$. &.$/ . .1$ & $r / V I$ & $.|| f \mid$ & D & كام سوم & \\
\hline
\end{tabular}

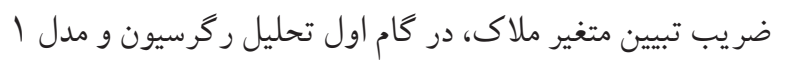

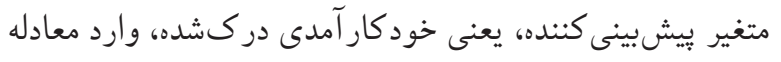

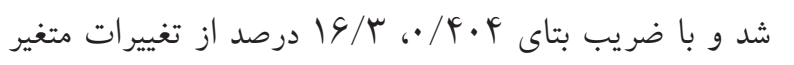

نتايج تحليل ركرسيون در جدول 4 نشان داد كه مشاهدهشده در متغير رفتارهاى مرتبط با رعايت مقررات درون

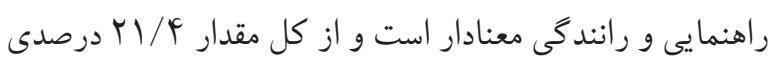


ميانگين نمره شدت دركشده در دختران نسبت به يسران بيشتر بود كه اين نتيجه كيرى با نتيجه مطالعه هزاوه ایى و همكاران

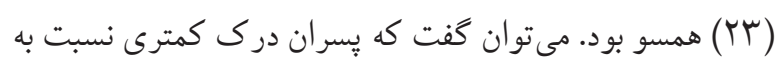

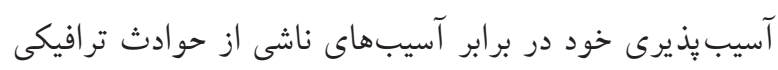

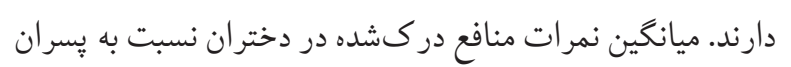

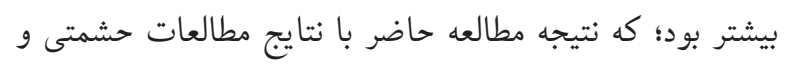

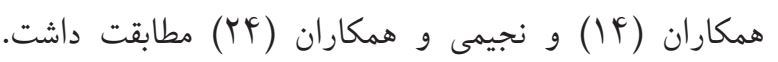

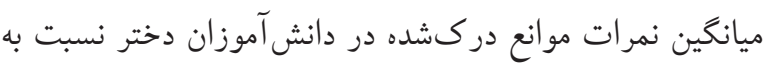

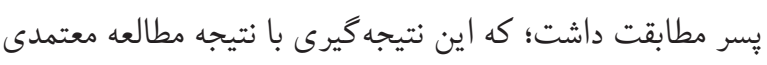

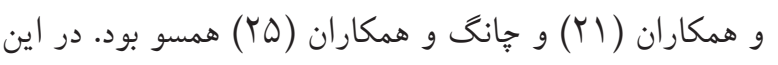

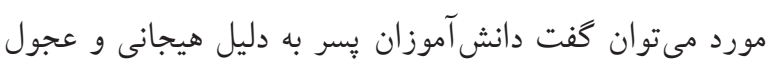
بودن هنكام عبور از عرض خيابان، يا تصور اينكه استفاده از يل وديل

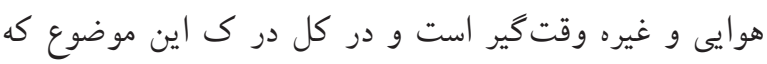

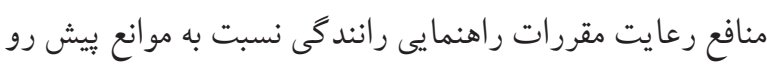
كمتر است، درى كمترى نسبت به غلبه بر موانع دارند.

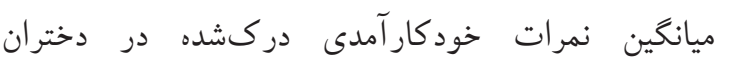

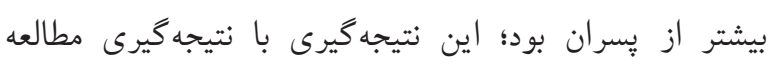

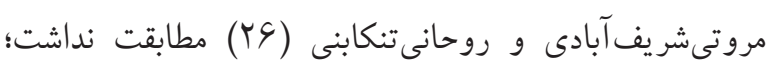

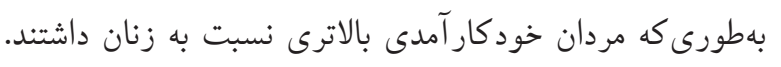
شايد دليل عمده آن عوامل اجتماعى و بهرهمندى بيشتر مردان

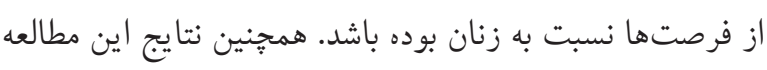

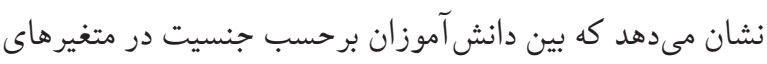
حساسيت دركشده، شدت دركشده، منافع دركشده و موانع

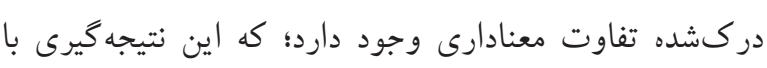
نتايج مطالعات معتمدى و همكاران (YI) و نجيمى و و همكاران

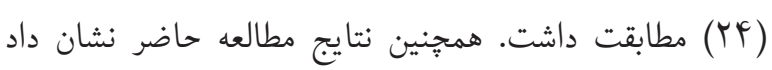

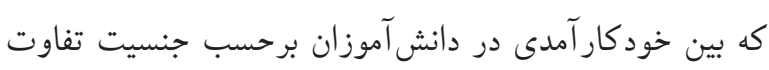

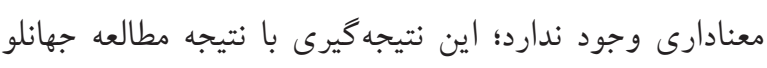

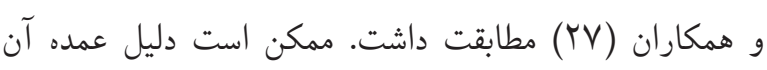
احساس ثبات اجتماعى بيشتر، حمايتهاى همسالان و تشويق

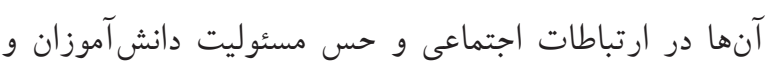

ملاك را تبيين كرد. در كام دوم و مدل Y متغير بيشبينى كننده

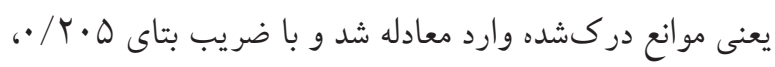

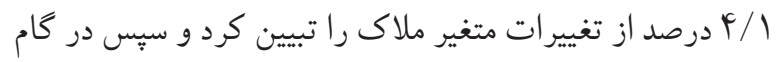

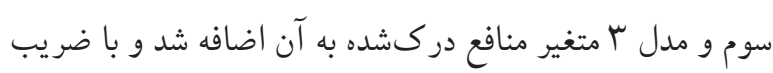

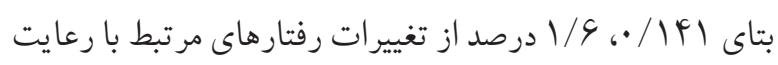

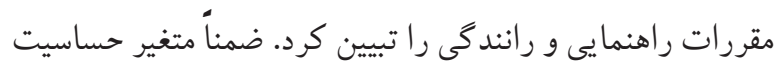
دركشده و شدت دركشده بيش بينى كننده معنادارى براى متغير

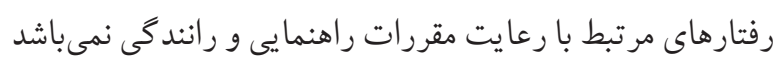
و درنتيجه در معادله رگرسيون وارد نشدند.

بحث يافتهاى اين يُووهش نشان داد كه رفتارهاى مرتبط با رعايت

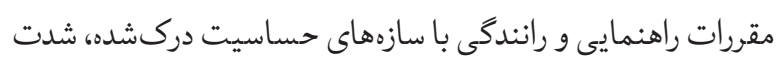

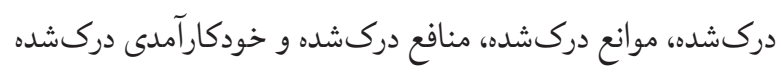

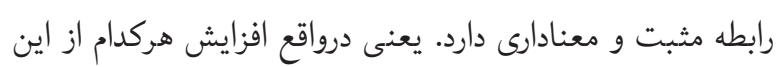

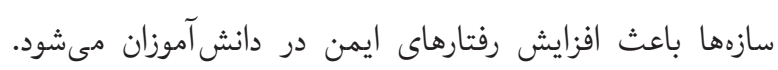

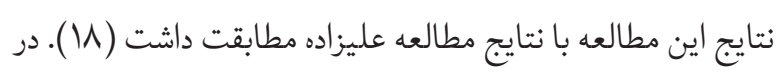
مطالعه جِن و همكاران (19) نيز منافع و خودكارآمدى دركشده

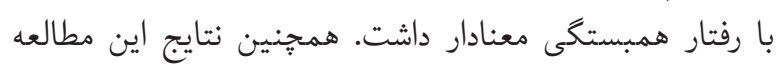
نشان داد كه متغيرهاى خودكارآمدى دركشده، موانع دركشده

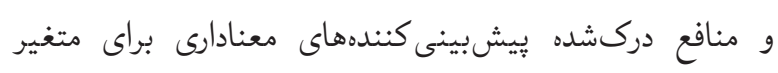

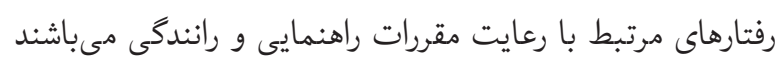

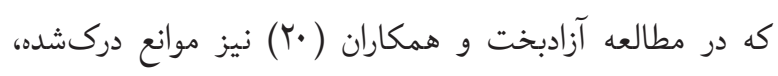
خودكارآمدى دركشده و شدت دركشده بهعنوان تعيين كنندهاى آداى

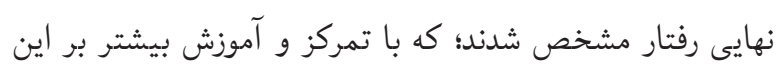

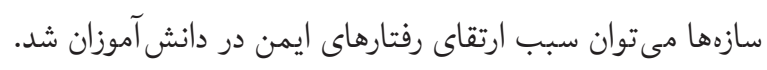

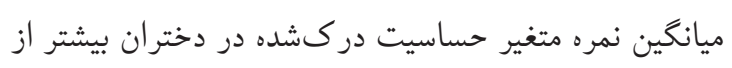
پِران بود؛ نتيجه اين مطالعه با نتيجه مطالعه معتمدى و همكاران

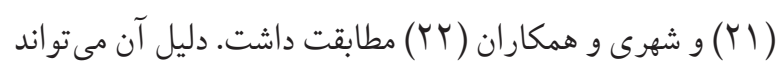
حساسيت بيشتر دختران نسبت به زيبايى و ظاهر خود نسبت به ونه يسران باشد ( آY). 
ترس در آنها و سازهايى مانند منافع و موانع دركشده سبب

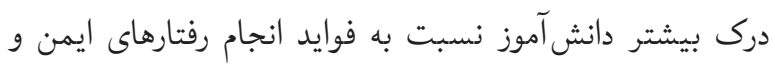

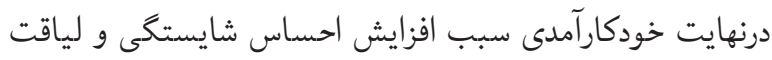

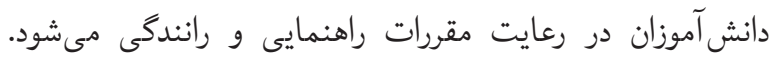
از طرفى با توجه به اينكه دانش آموزان يكى از آسيب

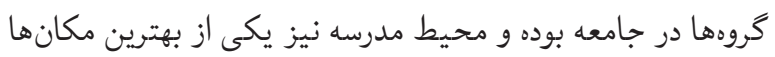

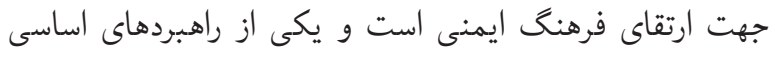
جهت كاهش حوادث ترافيكى و صدمات جادهاى آموزش است، بيشنهاد مى شود كه در يزوهشهاى آتى با استفاده از الخوى اعتقاد

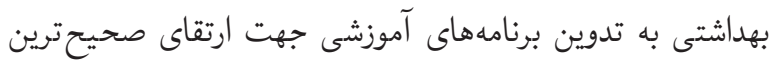

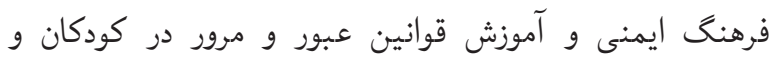
نوجوانان برداخته شود.

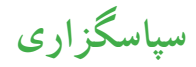

اين مقاله بركرفته از پاياننامه كارشناسىارشد آموزش بهداشت و

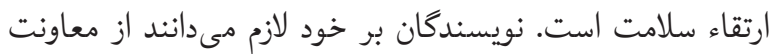
محترم تحقيقات و فناورى دانشگاه علوم يُشكى البرز به لحاظ

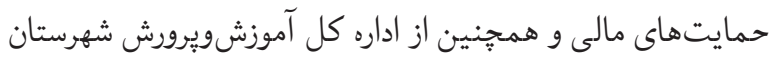

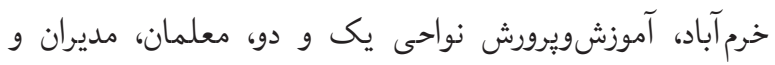

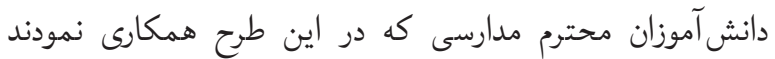
تشكر و قدردانى نمايند.

\section{References:}

1. Sherafati, A, Kashfi, S, Mehmandar, M. Factors affecting management of road accidents Lorestan Province. Lahoor. 2013;10(22):31-53. [Persian]

2. Mohtasham Amiri Z, Yousefzadeh-Chabok SH, Haghdoust $\mathrm{Z}$, Hemmati H. Road traffic injuries are life-threatening phenomenon in Gilan. J Guilan Univ Med Sci. 2014;1:8-23. [Persian]

3. Herman J, Ameratunga S, Jackson R. Burden of road traffic injuries and related risk factors in low and middle-income Pacific Island countries and territories: a systematic review of the scientific literature (TRIP 5). BMC Public Health. 2012;12:479.

4. Peden M. World report on child injury prevention appeals to "Keep Kids Safe". Inj Prev. 2008;14(6):413-4.
مفيد بودن آنها در جامعه و درنهايت داشتن خودكارآمدى در رعايت مقررات راهنمايى و رانندگى در هردو جنس و در اين كروه سنى باشد.

در اين مطالعه ميانكين نمرات رفتار در دانشآموزان دختر نسبت به دانش آموزان يسر بيشتر بود. اين نتيجه گيرى با نتايج مطالعه مروتىشريفآباد و همكاران (YN) مطابقت داشت. همجنين در مطالعه صادق نزاد و همكاران(Yq) نيز زنان در هنگام رانندگى بيشتر از مردان از كمربند ايمنى استفاده مى كردند. دليل اين امر مىتواند برانخيختهشدن كمتر بسران در زمينه ترس از انجام رفتارهاى يرخطر يا تأثير گروه همسالان مانند ترس از مورد تمسخر قراركرفتن توسط آنها و درنهايت انجام رفتارهاى غير ايمن باشد. نتيجها گَيرى: در كل مىتوان كفت در مقايسه بين نمرات سازهاى الكوى اعتقاد بهداشتى و رفتار، دانش آموزان دختر نسبت به دانشآموزان يسر آكاهى بيشترى داشته و بالاترين نمرات سازهاى الخوى اعتقاد بهداشتى و رفتار را دارند. درصورتى كه دانشآموزان ڤِر ممكن است بيشتر در معرض آسيبهاى ناشى از حوادث ترافيكى باشند. لذا استفاده از روشهاى آموزشى لئى مبتنى بر الخوهاى بهداشتى و بهخصوص الخوى اعتقاد بهداشتى به دليل تمركز بر سازههايى مانند حساسيت و شدت دركشده

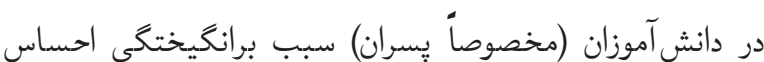

5. Cao ZJ, Chen Y, Wang SM. Health belief model based evaluation of school health education programme for injury prevention among high school students in the community context. BMC Public Health. 2014;14:26-34.

6. Bayan P, Bhawalkar JS, Jadhav SL, Banerjee A. Profile of non-fatal injuries due to road traffic accidents from a industrial town in India. Int J Crit IIIn Inj Sci. 2013;3(1):8-11.

7. Montazeri A. Road-traffic-related mortality in Iran: a descriptive study. Public Health. 2004;118(2):110-3.

8. zamani alavijeh F, Ahmadi Engali K, Nadi Baghoo M, Dalf Zargani $\mathrm{H}$, Taghi Rahdari M. Damages driving in hospital clients Masjed Soleiman. Payesh J. 2012;12(1):45-52. [Persian]

9. Matin H, Afkari ME, Taghdisi MH. Promote safe behaviors 
boys primary school students based on Precede-Proceed Model. J Health Prom Health Educ. 2012;1(1):21. [Persian]

10. Yaghoobi $H$. Examines the role of human factors in the incidence of traffic accidents in Iran. J Psychiatr Clin Psycol Think Behav. 2000;6(1):60-7. [Persian]

11. Ashoogh M, Aghamolaei T, Ghanbarnejad A, Tajvar A. Application of the theory of planned behavior to predict the safety behavior of truck drivers. Health Educ Prom Health. 2013;1(3):5-14. [Persian]

12. Maduakonam DE, Miriam DU, Arthur N. Retrospections on Road Traffic Injuries as a Social Burden: The Role of Public Health Education Initiatives in a Developing Country. Niger J Med. 2015;24(2):169-74.

13. Tajedini M, Norouzi D. The impact of games on learning signs traffic regulations. Stud Traffic Manag Rahvar. 2012;1(2). [Persian]

14. Heshmati H, Behnampour N, Binaei G, Khajavai S. Determinants of Behavior of Students as Pedestrian and Car Occupants in Relation to Traffic Laws in 2013, Gorgan, Iran; An Application of Health Belief Model. Bull Emerg Trauma. 2014;2(3):115-20.

15. Vahedian-Shahroodi M, Elaheh L-m, Esmaily $H$, Tehrani $\mathrm{H}$, Hamidreza $\mathrm{M}-\mathrm{H}$. Prediction of osteoporosis preventive behaviors using the Health Belief Model. Iranian Journal of Health Education and Health Promotion. 2014;2(3):199207. [Persian]

16. Waylen A, Mckenna F. Cradle Attitudes - Grave Consequences-The Development of Gender Differences in Risky Attitudes and Behaviour in Road Use. Transport Res Lab2002..

17. Sherafati A, Kashfi S, Mehmandar M. Factors affecting the management of road traffic accidents author of Job. Rahvar Q. 2012;22(10).

18. Alizadeh Sivaki H, Jadgal KM, Shojaeian Razavi N, Zareban I, Heshmati H, Saghi N. Effect of education based on health belief model of nutritional behaviors of elementary school students in the city of Torbat 91. J Health Hygiene. 2014;5(4):289-99. [Persian]

19. Chen $\mathrm{CH}$, Chiu PJ, Chih YC, Yeh GL. Determinants of influenza vaccination among young Taiwanese children. Vaccine. 2015;33(16):1992-8.

20. Azadbakht M, Garmaroodi G, Taheri Tanjani P, Sahaf R,
Shojaeizade D, Gheisvandi. Health Promoting Self-Care Behaviors and Its Related Factors in Elderly: Application of Health Belief Model. J Educ Commun Health 2014;1(2):209. [Persian]

21. Motamedi N, Hejazi SH, Hazavehei SMM, Zamani AR, Saberi S, Rahimi E. Effect of education based on Health Belief Model on promoting preventive behavior of coetaneous leishmaniasis. J Mil Med. 2012;11(4):231-6. [Persian]

22. Shehri S, Abdel-Fattah M, Hifnawy TSS-. Knowledge and concern about avian influenza among secondary school students in Taif, Saudi Arabia. East Mediterr Health J. 2006;12(Suppl 2):178-88.

23. Hazavei SMM, Sohrabi Vafa M, Moeini B, Soltanian AR, Rezaei L. Assessment of oral - dental health status: using Health Belief Model (HBM) in first grade guidance school students in Hamadan. Jundishapoor J Health Sci. 2012;4(3):65-75. [Persian]

24. Najimi A, Alidoosti M, Moazemi Goodarzi A. Preventing influenza type $A$ behavior based on health belief model. J Health System Res. 2010;6(1). [Persian]

25. Zhang LL, Dalal K, Wang SM. Injury related risk behaviour: a Health belief model-based study of primary school students in a safe community in Shanghai. PLoS One. 2013;8(8):e70563.

26. Morowatisharifabad M, Tonekaboni NR. Per-ceived selfefficacy in self-care behaviors among diabetic patients referring to Yazd Diabetes Re-search Center. J Birjand Univ Med Sci. 2009;15(4):91-9. [Persian]

27. Shahab Jahanloo A, Ghofranipour F, Vafaee M, Kimiyagar M, Heydarnia AR, Sobhanei AR. Testing Helth Belief Model With HbA1c In Diabetic Patients. Hormozgan Med J. 2008;12(1):37-42.

28. Morowatisharifabad MA, Momeni Sarvestani $M$, Barkhordari Firoozabadi A, Fallahzadeh H. Predictors of unsafe driving in the city of Yazd on protection motivation theory in year 1389. Ofogh-e-Danesh J Gonabad Univ Med Sci. 2012;18(1):49-59. [Persian]

29. Sadeghnejad F, Niknami S, Montazeri A, Heydarnia A. Safety belt use among drivers and front passengers in Tehran: findings from observations and an interview survey. J Iran Inst Health Sci Res. 2014;177:13-87. [Persian] 